\title{
Study of heritability, genetic advance and variability in scoparia dulcis L.
}

\begin{abstract}
Background: The capacity of genotype to express different phenotypes in different environments is phenotypic plasticity and for any crop improvement it depends on magnitude of genetic variability present in base population. Environmental effects influence the total observable variations of quantitative traits. Therefore, partitioning of overall variance due to genetic and non-genetic causes becomes necessary for effective breeding programme. The heritability, genetic advance and variability of the medicinally important plant Scoparia dulcis L. was studied presently. All the traits studied in the case of $S$. dulsis excluding leaf area showed significant variation at $1 \%$ level of significance showing the significance of variation between them in the case of the characters. Genotypic coefficients of variation were also lower in all the cases of significant variation when compared to phenotypic coefficients of variation showing the different levels of influence of environmental factors on the expression of the traits under study. In the case of growth traits, the highest heritability were shown by leaf area and the genetic advance was found to be the highest in inter nodal length.
\end{abstract}

Keywords: Scoparia dulcis L., phenotypic variance, genotypic variance, genetic advance, heritability
Volume 2 Issue 4 - 2018

\author{
Chandramohanan KT, Neethu Narayanan \\ Post Graduate Department of Botany, Government Brennen \\ College, India
}

Correspondence: Chandramohanan KT, Post Graduate Department of Botany, Government Brennen College, Thalassery, Kerala, India, Tel +9194 47547217 , Email chandrubrennen@gmail.com

Received: June 15, 2018 | Published: July 24, 2018

\section{Introduction}

Individual organisms can alter their development, physiology and life history depending on environmental conditions. These environmental responses are both trait and resource specific, and represent evolved characteristics that vary among genotypes, populations and species. ${ }^{1}$ The capacity of genotype to express different phenotypes in different environments, phenotypic plasticity and for any crop improvement it depends on magnitude of genetic variability present in base population. ${ }^{2}$ Environmental effects influence the total observable variations of quantitative traits. Therefore, partitioning of overall variance due to genetic and non-genetic causes becomes necessary for effective breeding programme. The genotypic coefficient of variation estimates the heritable variability, whereas phenotypic component measures the role of environment on the genotype. High phenotypic coefficient of variation and low genotypic coefficient of variation for a character indicated high influence of environment in its expression. The phenomenon of transmission of characters from parents to offspring is usually measured in terms of heritability. Therefore the estimates of heritability and genetic advance would help to formulate a sound breeding programme. The heritability, genetic advance and variability of the medicinally important plant Scoparia dulcis L. of the family Plantaginaceae was studied presently.

The plant selected for the present study is $S$. dulcis. It is native to South America and it was introduced in to India in 1843. It is a perennial herb found in almost all localities, mainly distributed in the tropical and sub tropical region. The plant grows abundantly in rainy season. The plant has been reported to have weed status also. The plant has short life cycle, it takes nearly three months. The plant has high power to overcome environmental stress. It is distributed on road side, pathways, salty areas, marshy and wet lands. The plant reproduces vegetatively and sexually. In wet areas the root system of the plant always active so new leafy branch arises from the base of the stem. As a result of sexual reproduction numerous seeds may form. These plants have high medicinal importance. The plant of $S$. dulcis is known to possess anti-diabetic activity, antiulcer activities antioxidant activity, anti-kidney stone activity, antimalarial activity, sedative, hypnotyic, antioxidant, antitumor, which supports the therapeutic effects claimed by traditional practitioners. The active principles present in $S$. dulcis have been shown to exhibit cytotoxic and antitumor activity. Traditionally the plant widely used for the treatment of kidney stone in the indigenous peoples of Kerala like Kurichyas. Study of folk medicine was largely conducted in Bangladesh, toothache and stomach trouble, bronchitis, gastric disorder, haemorrhoids, insect bite, skin wound and hypertension etc. High medicinal importance of the plant is due to the presence of various chemical compounds like terpenoids, phenols, steroids, coumarins, phenols, saponins, tannins, amino acids, catecholamine, noradrenaline, adrenaline (having sympathomimetic effects), acacetin, amyrin, apigenin, benzoxazin. ${ }^{3}$ In Sanskrit literature it is mentioned for the treatments of kidney stone, and so it is commonly known in Malayalam as kallurukki.

When compared to other medicinal plant, this plant may show wide distribution. This phenotypic plasticity is influenced by both genetic and phenotypic traits. The main aim of the present study is to analyse the variation present within the species of S.dulcis understanding the source of phenotypic variation and response of organism with the environment. Variation in the phenotypic traits may be a product of current environmental differences between sites (phenotypic plasticity), a product of heritable differences (genotype differences=ecotypes) between the subpopulations at different sites, or a combination of both. ${ }^{4}$

\section{Materials and methods}

The area of the present study is extended mainly in three North Malabar districts of Kerala, India: Kasargod, Kannur and Kozhikode (Table 1). These three districts are characterised by the presence of Malabar Coast, influence of Western Ghats and the tropical climatic condition. 
Table I Accessions collected for the present study.

\begin{tabular}{|c|c|c|c|}
\hline Accession number & Place of collection & Panchayat/municipality & District \\
\hline BR I & Dharmadam, & Dharmadam grama panchayat & Kannur \\
\hline BR 2 & Chettipeedika, & Puzhati grama panchayat & Kannur \\
\hline BR 3 & Kanayanoor, & Chemilode grama panchayat & Kannur \\
\hline BR 4 & Mayyil & Mayyil grama panchayat & Kannur \\
\hline BR 5 & Chelora, & Chelora grama Panchayat & Kannur \\
\hline BR 6 & Kadamboor, & Kadamboor grama panchayat & Kannur \\
\hline BR 7 & Panerichal, & Peralassery grama panchayat & Kannur \\
\hline BR 8 & Kadachira, & Kadamboor grama panchayat & Kannur \\
\hline BR 9 & Panayathamparamba, & Anjarakandy grama panchayat & Kannur \\
\hline BR I0 & Marakkarkandi, & Kannur coorporation & Kannur \\
\hline BR II & Karivallur, & Peralam grama panchayat & Kasargod \\
\hline BR 12 & Kalikkadavu, & Pilicode gramapanchayat & Kasargod \\
\hline BR I3 & Kulam, & Cheruvattur panchayath & Kasargod \\
\hline BR I4 & Kanjangad, & Kanjangad block panchayat & Kasargod \\
\hline BR I5 & Cheruvathoor, & Cheruvathur grama panchayat & Kasargod \\
\hline BR 16 & Nileswaram, & NileswaramMunicipality & Kasargod \\
\hline BR 17 & Railway station, & Kasarkode municipality & Kasargod \\
\hline BR 18 & KSRTC bus stand, & Kasarkode municipality & Kasargod \\
\hline BR 19 & Cherkkala, & Cherkala gramapanchayat & Kasargod \\
\hline BR 20 & Madur & Madur grama panchayat & Kasargod \\
\hline BR 2I & Ramanattukara & Ramanattukara grama panchayat & Kozhikode \\
\hline BR 22 & Medical college & Kozhikode corporation & Kozhikode \\
\hline BR 23 & Kunnamangalam, & Kunnamangalam grama panchayat & Kozhikode \\
\hline BR 24 & Civil station & Kozhikode corporation & Kozhikode \\
\hline BR 25 & Mananchira & Kozhikode corporation & Kozhikode \\
\hline BR 26 & Beypur & Nallalam grama panchayat & Kozhikode \\
\hline BR 27 & Meenchanda & Kozhikode corporation & Kozhikode \\
\hline BR 28 & Railway station & Kozhikode coorporation & Kozhikode \\
\hline BR 29 & Farok & Farok municipality & Kozhikode \\
\hline BR 30 & Idimuzhikkal & Farok municipality & Kozhikode \\
\hline
\end{tabular}

For the present study the fields were frequently visited and the observations were made on required aspects. Plants from thirty accessions (Table 1), ten accessions each from Kasargod, Kannur and Kozhikode districts were collected and analysed. Nine plants were collected from each accession randomly. Data were collected for three consecutive growing seasons of 2016-17. Nine genetically stabled morphometric characters viz length of tap root, number of secondary roots, length of main shoot, number of primary branches, length of primary branch, number of secondary branches, number of nodes on primary branches, inter nodal length and leaf area were studied.

Collected data were statistically analysed for variability of traits by using Analysis of variance (ANOVA). Analysis of variance (ANOVA) was carried out to test the significance of variations in terms of the different characters studied presently. F value was calculated for the purpose and Test of significance was done with reference to standard F-Table. ${ }^{5} \mathrm{CD}$ was calculated with the formula:

$$
C D=t_{0.05} x \sqrt{2 V E / r}
$$

Where $t_{0.05}$ is $t_{0.05}$ for error degree of freedom; VE is the error mean square and $r$ the number of replications. Phenotypic and genotypic variances for the different characters were estimated as per Singh \& Choudhary ${ }^{6}$ using the formula:

$$
\begin{aligned}
& \text { Genotypic Variance }\left(\sigma^{2} g\right)=\frac{\text { MSS for treatment }- \text { MSS for error }}{\text { Number of replications. }} \\
& \text { Phenotypic Variance }\left(\sigma^{2} p\right)=\sigma^{2} g+\sigma^{2} e
\end{aligned}
$$

Where $\sigma^{2} e$ is the error variance. Coefficients of variation provide information on the extent of variability of characters as percentage of the corresponding mean values of the characters. Phenotypic and genotypic coefficients of variation were estimated following Burton \& Devane. ${ }^{7}$ 
Genotypic coefficient of variation $(G C V)=\frac{\sigma g \times 100}{\bar{X}}$

Where $\sigma g=$ the genotypic standard deviation and $\bar{X}=$ grand mean of the character.

$$
\text { Phenotypic coefficient of variation }(P C V)=\frac{\sigma p \times 100}{\bar{X}}
$$

Where $\sigma p=$ the phenotypic standard deviation.

Heritability (broad sense) is estimated as the percentage of genotypic variance over phenotypic variance. ${ }^{8}$ Genetic advance is the genetic improvement of the progeny possible through selection over the original population. Genetic advance was calculated using the following formula:

$$
G A=\frac{K H^{2} \sigma p}{\bar{X}}
$$

Where $H^{2}=$ heritability (broad sense); $\sigma p=$ phenotypic standard deviation; $K=$ selection differential which is 2.06 at $5 \%$ intensity of selection in large samples. ${ }^{9}$

Table 2 Genotypic variance, phenotypic variance, genotypic coefficient of variation, phenotypic coefficient of variation, heritability (broad sense) and genetic

\begin{tabular}{|c|c|c|c|c|c|}
\hline \multicolumn{6}{|l|}{ Characters } \\
\hline Genotypic variance & $\begin{array}{l}\text { Phenotypic } \\
\text { variance }\end{array}$ & GCV (\%) & PCV (\%) & Heritability & $\begin{array}{l}\text { Genetic } \\
\text { advance }\end{array}$ \\
\hline \multicolumn{6}{|l|}{ I. Length of tap root } \\
\hline 2.8 & 5.89 & 15.45 & 22.16 & 48.59 & 22.18 \\
\hline \multicolumn{6}{|c|}{ 2. No. of secondary root } \\
\hline 4.52 & 18.42 & 13.8 & 27.85 & 24.56 & 14.09 \\
\hline \multicolumn{6}{|l|}{ 3. Length of main stem } \\
\hline 18.65 & 61.2 & 16.17 & 16.17 & 30.48 & 18.39 \\
\hline \multicolumn{6}{|c|}{ 4. No. of primary branches } \\
\hline 1.83 & 7.6 & 24.96 & 50.85 & 24.09 & 25.23 \\
\hline \multicolumn{6}{|c|}{ 5. No. of secondary branches } \\
\hline 2.86 & 16.65 & 28.05 & 67.68 & 17.18 & 23.96 \\
\hline \multicolumn{6}{|c|}{ 6. Length of primary branch } \\
\hline 4.68 & 37.65 & 12.68 & 35.95 & 12.45 & 9.21 \\
\hline \multicolumn{6}{|l|}{ 7. No.of nodes } \\
\hline 4.36 & 12.69 & 13.83 & 23.59 & 34.38 & 16.71 \\
\hline \multicolumn{6}{|l|}{ 8. Inter nodal length } \\
\hline 2.32 & 5.5 & 71.88 & 90.6 & 42.25 & 96.24 \\
\hline \multicolumn{6}{|l|}{ 9. Leaf area } \\
\hline 0.63 & 1.29 & 53.12 & 76.19 & 48.61 & 76.3 \\
\hline
\end{tabular}
advance in the case of 9 characters of Scopariadulcis L.

In $S . d u l s i s$, in all the cases of significant variation, phenotypic variance was higher than genotypic variance indicating the polygenic nature of the traits under study and also the involvement of additive genes in the control of the characters. Genotypic coefficients of variation were also lower in all the cases of significant variation when compared to phenotypic coefficients of variation showing the different

\section{Results and discussion}

The existence and progression of a genetic stock is governed by the magnitude of genetic variability accessible in terms of heritable traits. Genetic improvement is generally accomplished by selecting the genotypes with desirable qualities from the available populations.

Analysis of variance is a statistical procedure to compare the extent of variations between populations with the extent of variations within populations so as to determine the significance of variability between populations or accessions..$^{10}$ All the traits studied in the case of $S$. dulsis excluding leaf area showed significant variation at $1 \%$ level of significance showing the significance of variation between them in the case of the characters. However, leaf area showed no significant variation showing that their variation is narrow between the accessions. The reason of this variability may be both genetic as well as environmental. Genotypic variation between cultivars or populations is the expression of their genetic differences and phenotypic variation is the result of interaction between genetic differences and environment. Genotypic and phenotypic variations have been studied presently in the case of 30 accessions of $S$. dulsis on genotypic variance, phenotypic variance, genotypic coefficient of variation and phenotypic coefficient of variation Table 2 . 
Heritability (broad sense) is the ability of a trait to get inherited to the progeny. Oligogenic traits show high heritability whereas the heritability of polygenic trait is controlled by the number of polygenes involved and the involvement of the environment on their expression. Most of the agronomic traits of $S$. dulsis are polygenic in nature and they show different levels of significance. In the case of $S$. dulsis, among the growth traits, the highest heritability were shown by leaf area (48.6) followed by length of tap root (48.6) and intermodal length $(42.3 \%)$. Heritability of number of primary branch and number of secondary branches was comparatively low thus showing the influence of environment on the expression of these traits.

Percentage of genetic advance possible under selection is a measure of the quantum of improvement possible and a parameter that can be used to find out the utility of characters in crop improvement programmes. In S. dulsis, among the growth characters studied, genetic advance was found to be the highest in inter nodal length $(96.2 \%)$ followed by leaf area $(76.3 \%)$. This shows that these characters can be effectively used for selecting superior genotypes.

\section{Acknowledgements}

None.

\section{Conflict of interest}

Authors declare there is no conflict of interest.

\section{References}

1. Sulthan SE. Phenotypic plasticity for plant development, function and life history. Trends in plant sciences: reviews. 2000;5(12):537-542.

2. Sulthan SE. Phenotypic plasticity and plant adaptation. Acta Botanica Neerlandica banner. 1995;44(4):363-383.

3. Okale SE, Amanabo MO, Jegede IA, et al. Phytochemical and Pharmacognostic Investigation of Antidiabetic Scoparia dulcis L. Scrophulariaceae Whole Plant Grown in Nigeria. Researcher.2010;2(6).

4. Blumer L. Phenotypic variation in plants. Canada: Association for Biology Laboratory Education (ABLE); 1996. p. 231-247.

5. Fischer RA, Yates F. Statistical Tables for Biological, Agricultural and Medical Research. England: Longman Publishers; 1963. 356 p.

6. Singh RK, Chaudhary BD. Biometrical Method in Quantitative Genetics Analysis. India: Kalyani Publishers; 1985.

7. Burton GW, Devane EM. Estimating heritability in tall fescue (Festuca arundinacea) from replicated clonal material. Agronomy Journal. $1953 ; 45: 478-481$.

8. Jain JP. Statistical Techniques in Quantitative Genetics. India: Tata McGraw Hill Co; 1982. 281 p.

9. Allard RW. Principles of Plant Breeding. USA: John Wiley\& Sons; $1960.485 \mathrm{p}$.

10. Rastogi VB. Fundamentals of Biostatistics. India: Ane books Pvt Ltd; 2009. $243 \mathrm{p}$. 